\title{
REVIEW \\ Breeding of Pest and Disease Resistant Potato Cultivars in Japan by Using Classical and Molecular Approaches
}

\author{
Kenji ASANO and Seiji TAMIYA* \\ Upland Farming Resource Research Division, NARO Hokkaido Agricultural Research Center \\ (Memuro, Hokkaido 082-0081, Japan)
}

\begin{abstract}
Potato (Solanum tuberosum L.) is among the most important upland crops cultivated for many end uses throughout Japan. Potatoes are consumed in different ways, such as table use, food processing, starch production, and others. At the same time, various cropping systems are adopted according to environmental conditions. Although potato-breeding programs in Japan are conducted by considering these demands, pest and disease resistance is one of the most important traits required for all modern cultivars. There are many pests and diseases affecting potato production in Japan, where conferring resistance against potato cyst nematodes, late blight, common scab, bacterial wilt, and viral diseases has become a main target of breeding. Artificial inoculation tests and cultivation in infested fields were traditionally conducted, in order to evaluate the levels of resistance among breeding materials. However, several DNA markers for pest and disease resistance genes have recently been developed for the selection of resistant genotypes. We have taken both approaches toward the selection of pest and disease resistant genotypes at each breeding step. This review introduces our approaches to develop new pest and disease resistant potato cultivars by using classical and molecular approaches.
\end{abstract}

Discipline: Plant breeding

Additional key words: marker-assisted selection, resistance test

\section{Introduction}

Potato (Solanum tuberosum L.) is one of the most important upland crops in Japan. With a total growing area of 81,200 ha, accounting for $1.8 \%$ of all cultivated land in Japan, 2,500,000 tons of potatoes were produced in 2012 (according to Japan's Ministry of Agriculture, Forestry and Fisheries). Potato cultivars in Japan are roughly classified into four categories based on end use: table use, food processing, starch production, and others. Moreover, because Japan is an arching archipelago stretching from north to south, where climate ranges from boreal to subtropical, potato growing seasons vary with different environmental conditions. In Hokkaido, Japan's largest potato production area located in the northernmost part of the country and in the boreal region, potatoes are grown in summer. In Kyushu, Japan's second largest production area and part of the southern warm region, double cropping is practiced whereby potatoes are grown in both spring and fall. These various cultivation environments in Japan require diverse cultivars (Mori et al. 2015). To cover the diverse demands for cultivars, the public sector has established two breeding stations in Hokkaido and two in Kyushu; in addition, two private companies have their own breeding project in Hokkaido.

Recommended potato cultivars must be suited to the expected end use and high yield, show proper growth for their growing area, exhibit high pest and disease resistances, etc. Among these desired traits, resistance to pests and diseases is necessary. Potatoes are vulnerable to pests and diseases that adversely affect leaves, stems, roots, and tubers. Up to $30 \%$ of world potato production is lost to these pests and diseases (Oerke et al. 1994). Various pests and diseases including potato cyst nematodes (PCN), late blight, common scab, soft rot, black leg, bacterial wilt, early blight, and several viral diseases affect potato production in Japan. Therefore, conferring resistance to these biotic stresses is a major objective in

*Corresponding author: stamiya@affrc.go.jp

Received 6 January 2015; accepted 1 June 2015. 
potato breeding. In this review, we provide an overview of methods to develop pest and disease resistant cultivars in Japan by using classical and molecular approaches.

\section{Breeding scheme for pest and disease resistant potato cultivars}

Fig. 1 shows a flowchart of potato breeding for pest and disease resistance at the NARO Hokkaido Agricultural Research Center. Similar breeding schemes with minor modifications are adopted in all potato-breeding programs in Japan. Progenies derived from crosses for disease resistance are subjected to resistance tests at early stages of breeding. At the final stage (the performance yield test), all lines are evaluated for resistance to late blight and common scab, while promising elite lines are also subjected to an evaluation of resistance to late blight, common scab, PVY, and bacterial wilt in the public sector (the test of specific characters). In addition to resistance evaluation at this final stage, several other evaluations (e.g. local adaptability test, the performance test for recommendable cultivars) are conducted. The lines selected

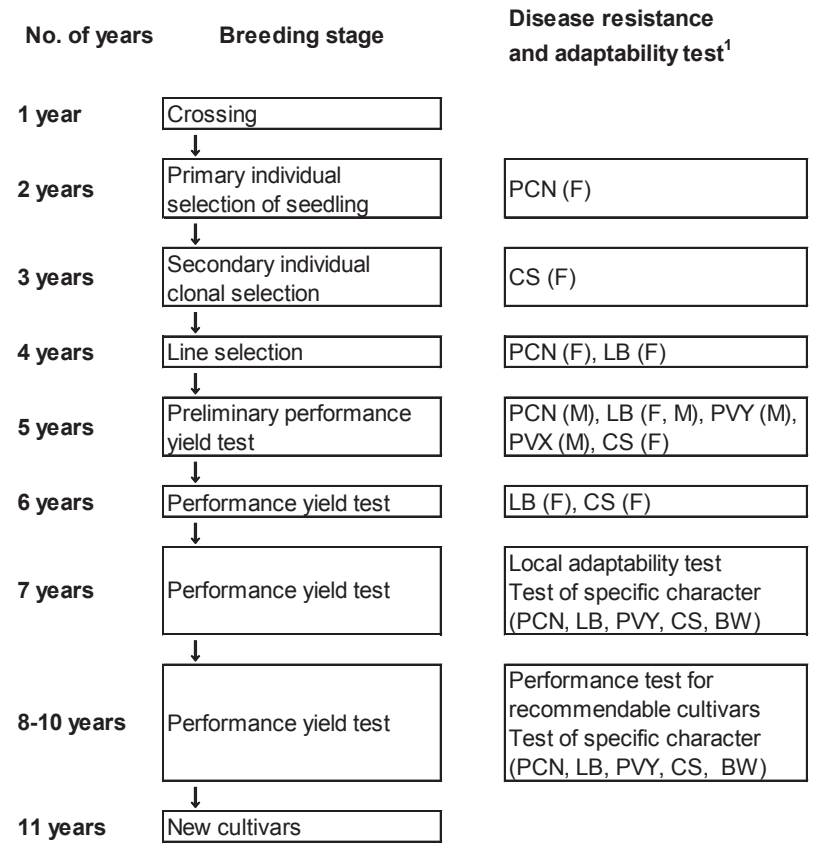

Fig. 1 Flowchart of potato breeding at the NARO Hokkaido Agricultural Research Center.

Resistance tests are conducted at each stage. CS: common scab. LB: late blight. BW: bacterial wilt. (F) Resistance tests are conducted by cultivation in infested fields or by artificial inoculation. (M): Marker Assisted Selection (MAS) is conducted by multiplex PCR to detect five markers for pest and disease resistance genes. The test of specific character is conducted by cultivation in infested fields or artificial inoculation for all diseases. based on the results of these tests are then released as new cultivars.

\section{Evaluation of pest/disease resistance by artificial inoculation and cultivation in infested fields}

Potato plants suffer many biotic stresses in the farming fields of Japan. In particular, PCN, late blight, common scab, bacterial wilt, and viral diseases, especially potato virus $\mathrm{Y}$ (PVY) and potato virus X (PVX), have become the main targets of resistance breeding. Artificial inoculation, cultivation in infested fields by a disease, and DNA marker-assisted selection (MAS) are used to evaluate the resistance to these pests and diseases. This section describes the first two of these evaluation methods.

\section{Potato cyst nematodes}

Plants infected by PCN show lower levels of growth, symptoms similar to those of water stress or nutrient deficiency, and a reduction of yield. PCN are comprised of two species-Globodera rostochiensis (Woll.) Behrens and G. pallida (Stone) Behrens - that include eight pathotypes (Ro1-5 of G. rostochiensis (Woll.) Behrens and Pa1-3 of G. pallida (Stone) Behrens) (Stevenson et al. 2001). Among the eight pathotypes, only Rol is known to be prevalent in Japan after being discovered in Hokkaido back in 1972 (Inagaki 1984). Nowadays, resistance to Ro1 is considered an essential trait for new potato cultivars in Japan. Therefore, a single dominant gene $(\mathrm{Hl})$ that confers nearly complete and durable resistance to
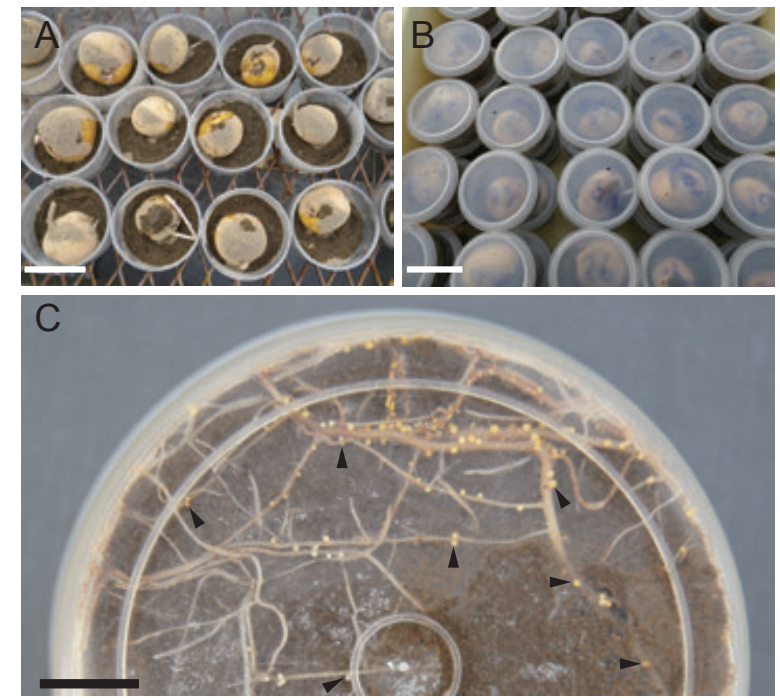

Fig. 2 The plastic cup method for the PCN resistance test. $\mathrm{A}$ and B: Tubers planted in small plastic containers $(B a r=5 \mathrm{~cm})$. C: Cysts formed on the roots of susceptible plant. Black arrowheads indicate typical cysts $(\operatorname{Bar}=1 \mathrm{~cm})$. 
pathotypes Ro1 and Ro4 (Huijsman 1955) is widely used to develop PCN resistant cultivars (Asano et al. 2012). PCN resistance is evaluated by cultivating potato plants in fields infested with PCN or by using the "plastic cup method' - a modified version of the screening method developed by Phillips et al. (1980). In this method, tubers are planted in small transparent plastic cups containing PCN-infested soil (Fig. 2), followed by cultivation at $20^{\circ} \mathrm{C}$ under dark conditions for about 70 days. After incubation, cysts are expected to form on the roots of susceptible lines (Fig. 2), but not on those of resistant lines, which are observable from outside the containers without opening the lid. This screening method is very easy, relatively quick, space saving, and cost-effective; in addition, it reduces the risk of environmental contamination by PCN as compared to test in fields infested with PCN. Selection of PCN resistant lines using this method are conducted at early breeding stages (from the primary individual selection of seedlings to line selection) (Fig. 1). Because PCN resistance is a prerequisite characteristic in Japan, lines without PCN resistance are discarded from the breeding process at these early stages.

\section{Late blight}

Late blight, which is caused by the oomycete pathogen Phytophthora infestans (Mont.) de Bary, is considered the most destructive disease affecting potato production worldwide (Stevenson et al. 2001). On

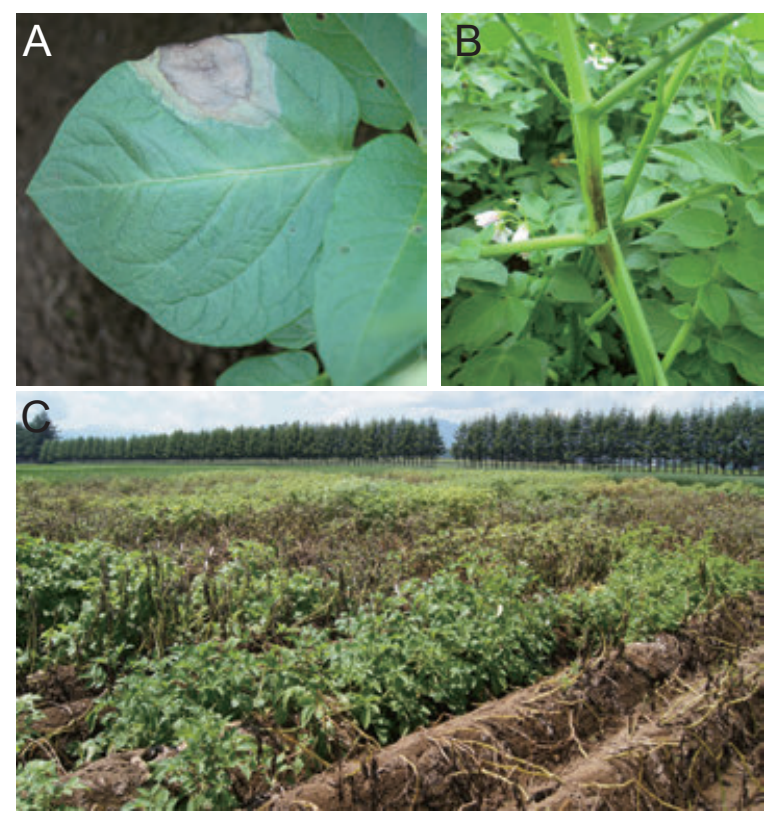

Fig. 3 Selection of late blight resistance lines in fields. Lesions formed on leaf (A) and stem (B). C: Expansion of late blight in infested fields. Resistant lines remain green until later stages. Photos were taken on the 10th (A and B) and 27th (C) of July 2014. infested plants, lesions that form on the leaves or stems rapidly expand and soon kill the plants (Fig. 3). Tubers are also affected by late blight during the stages of growth, harvest, and storage. The control of late blight in Japan generally relies on the frequent application of fungicides. Eleven hypersensitivity-type resistance genes ( $R$ genes) against $P$. infestans had been introgressed into potato cultivars from the wild species $S$. demissum Lindl. (Black et al. 1953). However, the rapid emergence of new races that overcame the $R$ genes resulted in a breakdown of resistance conferred by $R$ genes (Fry et al. 1993). Thus, a major goal in the development of resistant cultivars is conferring field resistance against $P$. infestans. Complicated treatments are not required to evaluate such field resistance. Generally speaking, fungicides are frequently sprayed onto potato plants in experimental fields and farmer's fields as well, in order to avoid natural infection by airborne inoculum of $P$. infestans. In evaluating field resistance to the disease, fungicides have not been applied to potato plants. Late blight rapidly expands throughout such infected fields due to a large volume of airborne natural inoculum, and then completely destroys susceptible lines in a short time. However, the spread of the disease is much slower on resistant lines than on susceptible lines (Fig. 3). Resistance is evaluated based on the area under the disease progress curve (AUDPC), which is a parameter calculated from the occasional evaluation of disease severities expressed as percentages of infected leaf area. Selection for late blight resistance is made at the line selection and in the preliminary performance yield test for crosses aimed at late blight resistance (Fig. 1). At Kitami Agricultural Experiment Station, resistant genotypes are also selected at the primary individual selection of seedlings by inoculating cultured pathogens for cross combinations, from which late blight resistant progenies are expected.

\section{Common scab}

Common scab is a serious soil-borne disease caused by Streptomyces species (Stevenson et al. 2001). Three species of S. scabies, S. turgidiscabies, and S. acidiscabies are causal pathogens in Japan (Miyajima et al. 1998; Takeuchi et al. 1996). Common scab that causes corky lesions on tuber surfaces also significantly reduces tuber quality. In order to control common scab, several strategies are adopted, such as crop rotation, soil and seed tuber disinfection, the incorporation of green manure, and reduction of soil $\mathrm{pH}$ (Stevenson et al. 2001). Although the mechanisms and inheritance of resistance to common scab are not yet well understood, resistance could be inherited in a considerably simple manner; thus, classical breeding efforts could improve resistance to common 
scab (Jansky 2000). Resistant genotype selection is conducted in a field infested with Streptomyces species. Infested fields developed by the cultivation of infected tubers over several years, although the use of infested fields is disadvantageous in that nonuniform distribution of the scab pathogen in a field and between fields. This low uniformity reduces the accuracy of evaluation and causes difficulties in evaluating large populations. As alternatives to the evaluations made in infested fields, several stable assays using cultured inoculum have been reported (Kobayashi et al. 2005, Sakamoto et al. 2011). Progenies derived from crosses aimed at common scab resistance are subjected to field selection in all stages from the secondary individual selection of seedlings (Fig. $1)$.

\section{Viral diseases}

Twelve viruses have been identified as causal agents of viral diseases affecting potatoes in Japan (Maoka et al. 2010). Among the 12 viruses, PVY is the most frequently found in Japanese potato production areas. All strains of PVY reduce yield and introduce symptoms such as crinkling, mosaicism, necrotic streaking, and tuber necrosis, which vary in line with the plant genotype, virus strain, environmental conditions, and their interactions. PVX causes very mild mosaicism and is often latent. Although the level of yield reduction caused by PVX infection alone is low, simultaneous infections with other viruses such as PVY and/or potato virus A lead to a severe reduction of yield. PVY is transmitted by aphids or via contact with infected plants. In contrast, aphids do not transmit PVX (Stevenson et al. 2001). The use of certified seeds with high quality is the most effective strategy to reduce viral diseases. Resistant cultivars possessing resistance genes against these viruses contribute to the production of high quality healthy seeds. Although several genes conferring extreme resistance against PVY and PVX have been reported (Asama et al. 1982, Cockerham 1943, Munoz et al. 1975, Ritter et al. 1991), only $R y_{c h c}$ and $R x l$ have been used in breeding for resistance to PVY and PVX in Japan (Mori et al. 2015). Resistance to both PVY and PVX has been finally confirmed by inoculating viruses mechanically. As cost-effective and labor-saving alternative methods relative to mechanical inoculation, DNA markers for $R y_{c h c}$ and $R x l$ have recently been developed and used for potato breeding in Japan (Takeuchi et al. 2008, Ohbayashi et al. 2010). (See Fig. 1, below.)

\section{Bacterial wilt}

Ralstonia solanacearum (Smith) Yabuuchi et al. causes bacterial wilt, which is very common in tropical and subtropical regions, and causes serious wilting in potato (Stevenson et al. 2001). Likewise, this disease tends to occur during both fall and winter cropping in the warmer regions of Japan. Because the disinfection of seeds and soil by using chemicals is ineffective, the cultivation of resistant cultivars is the most effective way to control the disease. S. phureja Juz. Et Buk. is known to carry resistance traits against this bacteria (Fock et al. 2000), and has been used as resistance source in Japan (Mori et al. 2012). The evaluation of resistance is based on disease severity and the percentages of infected and dead plants in fields naturally infested with $R$. solanacearum. Because bacterial wilt occurs in warm regions, breeding stations located in the warm region of Kyushu introduce and evaluate resistance to the disease.

\section{DNA marker-assisted selection for pest and disease resistance}

To evaluate pest and disease resistance, bioassays in greenhouses or infested fields are important and fundamental, but also time- and space-consuming, require advanced techniques. The application of DNA markers offers numerous advantages in terms of saving time, for consistency, biosafety, efficiency, and a more accurate selection of complex traits. To date, various kinds of DNA markers for the resistance to pests and diseases, including PCN (H1, Grol-4, and Gpa2), late blight (R1 and $R 2)$, PVY ( $R y_{c h c}, R y_{a d g}$, and $\left.R y_{\text {sto }}\right)$, and PVX (Rxl), have been developed (Asano et al. 2012, Ahmadvand et al. 2013, Ballvora et al. 2002, Kasai et al. 2000, Takeuchi et al. 2008, Ohbayashi et al. 2010, Song and Schwarzfischer 2008). Regarding PCN resistance, it is possible to simultaneously detect the three PCN resistance genes by multiplex PCR, which was applied to survey the potential of resistance genes in Japanese genetic resources (Fig. 4). The detection of PCN resistance genes by using DNA markers is quite beneficial in Japan. In cases

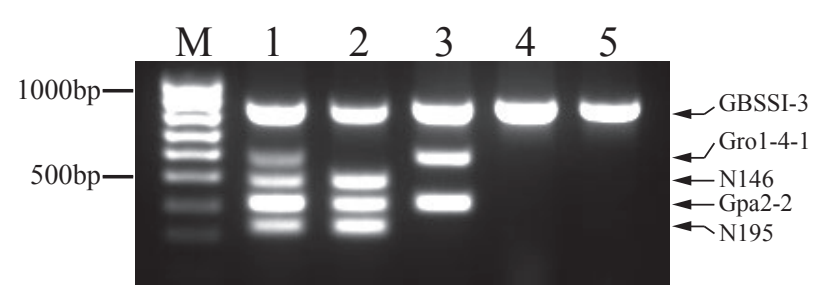

Fig. 4 Simultaneous detection of DNA markers for three $\mathrm{PCN}$ resistance genes.

DNA markers for $\mathrm{Hl}$ (N146 and N195), Grol-4 (Gro1-4-1), and Gpa2 (Gpa2-2) are simultaneously detected in a single reaction with positive controls (GBSS1-3). M, 100-bp marker; 1, DNA mixture (Touya + Alwara); 2, Touya; 3, Alwara; 4, Irish Cobbler; 5, May Queen. 
where breeders try to evaluate the PCN resistance genes against pathotypes, which have not invaded Japan, it would be risky to import the living organism for bioassay. However, precise DNA markers allow breeders to identify the resistance genes without using the living nematodes (Asano et al. 2012). The method of detecting five markers $\left(H 1, R 1, R 2, R y_{c h c}\right.$, and $\left.R x 1\right)$ in a single reaction has been used in Japan to select genotypes with multiple resistances (Mori et al. 2011). The lines selected based on MAS are then evaluated for other agronomic characteristics, with disease resistance being confirmed by an inoculation test or field evaluation at later stages. DNA markers are also useful in determining the gene dosage of resistance genes. In considering the resistance controlled by single dominant loci, multiplex genotypes for the resistance genes ( $R R R R$ or $R R R r$ or $R R r r)$ give rise to resistant progenies at a higher frequency than do simplex genotypes (Rrrr). Therefore, parental lines with multiplex genotype would be preferable. Multiplex genotypes have traditionally been determined by a progeny test. As a modern technique, we developed a rapid and easy selection method for multiplex genotypes for $H 1$ and $R y_{\text {chc }}$ using a quantitative PCR method (Asano and Tamiya 2013). This method is considered to contribute to the efficient selection of multiplex genotypes from large populations.

\section{Future perspectives}

The average temperatures in potato production areas are predicted to increase 1.6 and $3.0^{\circ} \mathrm{C}$ between 2040 and 2069 (Hijmans 2003). Along with this predicted increase in temperature, the range of climate fluctuation is expected to become wider (Hirota et al. 2011), resulting in an increased risk of pests and diseases, including late blight, bacterial soft lot, bacterial wilt, potato tuber moth, and aphids. Therefore, the breeding of resistant cultivars will become even more important. In addition to conferring resistance to pests and diseases, improvements in other characteristics such as yield, quality, and cultivation-related characteristics are also important in developing superior cultivars that will replace older ones. To date, several pest and disease resistant cultivars have been developed, although many older cultivars such as Irish Cobbler, May Queen, Nishiyutaka, Toyoshiro, and Konafubuki are still occupy the position of leading cultivars, even though they lack sufficient disease resistance, thereby posing another risk of a severe outbreak of pests or disease. Therefore, efficient breeding is important in order to promote the development of superior resistant cultivars. We are currently selecting potato clones with multiple copies of $R y_{c h c}$ to accelerate the breeding of
PVY resistant cultivars. Aside from these diseases, DNA markers for common scab resistance and others are now being developed. Improvements in pest and disease resistance, quality, and cultivation-related characteristics achieved through these approaches will thus lead to the development of innovative cultivars.

\section{References}

Asama, K. et al. (1982) New potato variety "Konafubuki." Hokkaido-ritsu nogyo shikenjo shuho (Bull. Hokkaido Pref. Agr. Exp. Stn.) 48, 75-84 [In Japanese with English summary].

Asano, K. et al. (2012) DNA marker-assisted evaluation of potato genotypes for potential resistance to potato cyst nematode pathotypes not yet invading into Japan. Breed. Sci. 62, 142-150.

Asano, K. \& Tamiya, S. (2013) Development of rapid estimation method for allele number of $H 1$ and selection of multiplex lines in potato. Ikushugaku kenkyu (Breed. Res.) 15 (suppl 1), 53 [In Japanese].

Ahmadvand, R. et al. (2013) Development of molecular tools for distinguishing between the highly similar $R x 1$ and $R x 2$ PVX extreme resistance genes in tetraploid potato. Potato Res. 56, 277-291.

Ballvora, A. et al. (2002) The Rl gene for potato resistance to late blight (Phytophthora infestans) belongs to the leucine zipper/NBS/LRR class of plant resistance genes. Plant J. 30, 361-371.

Black, W. et al. (1953) A proposal for an international nomenclature of races of Phytophthora infestans and of genes controlling immunity in Solanum demissum derivatives. Euphytica 2, 173-179.

Cockerham, G. (1943) Potato breeding for virus resistance. Ann. Appl. Biol. 30, 105-108.

Fock, I. et al. (2000) Resistance to bacterial wilt in somatic hybrids between Solanum tuberosum and Solanum phureja. Plant Sci. 160, 165-176.

Fry, W.E., Goodwin, A.T. Dyer, J.M. Matuszak, A. Drenth, P.W. Tooley, L.S. Sujkowski, Y.J. Koh, B.A. Cohen, L.J. Spielman et al. (1993) Historical and recent migrations of Phytophthora infestans chronology, pathways, and implications. Plant Dis. 77, 653-661.

Hijmans, R.J. (2003) The effect of climate change on global potato production. Am. J. Potato Res. 80, 271-279.

Hirota, T. et al. (2011) Climatic features of spring to summer in 2010 and their impact on agriculture in Hokkaido. Hokkaido nogyo kenkyu senta kenkyu shiryo (Misc. Pub. NARO Hokkaido Agric. Res. Cent.) 69, 1-13 [In Japanese with English summary].

Huijsman, C.A. (1955) Breeding for resistance to the potato root eelworm. II. Data on the inheritance of resistance in Andigenum-Tuberosum crosses obtained in 1954. Euphytica 4, 133-140.

Inagaki, H. (1984) Studies on the ecology and control of the potato cyst nematode, Globodera rostchiensis. Res. Bull. Hokkaido Natl. Agric. Exp. Stn. 139, 71.

Jansky, S. (2000) Breeding for disease resistance in potato. In: Janick, J. (eds.) Plant breeding reviews. John Wiley \& Sons, Inc., New York. 69-155. 
Kasai, K. et al. (2000) Development of SCAR markers to the PVY resistance gene Ryadg based on a common feature of plant disease resistance genes. Genome 43, 1-8.

Kobayashi, A. et al. (2005) Precise, simple screening for resistance in potato cultivars to common scab using paper pots. J. Gen. Plant Pathol. 71, 139-143.

Maoka, T. et al. (2010) Application of cDNA Macroarray for Simultaneous Detection of 12 Potato Viruses. Plant Dis. 94, 1248-1254.

Miyajima, K. et al. (1998) Streptomyces turgidiscabies sp. nov. J. Syst. Bacteriol. 48, 495-502.

Mori, K. et al. (2011) Development of a multiplex PCR method for simultaneous detection of diagnostic DNA markers of five disease and pest resistance genes in potato. Euphytica 180, 347-355.

Mori, K. et al. (2012) Germplasm release: Saikai 35, a male and female fertile breeding line carrying Solanum phureja-derived cytoplasm and potato cyst nematode resistance $(H 1)$ and potato virus $\mathrm{Y}$ resistance $(R y c h c)$ genes. Am. J. Potato Res. 89, 63-72.

Mori, K. et al. (2015) Challenges on breeding potato cultivars to grow in various environments and to meet different demands. Breed. Sci. 65, 3-16.

Munoz, F.J. et al. (1975) Resistance to potato virus Y in Solanum tuberosum ssp. andigena. Am. J. Potato Res. 52, 107-115.

Oerke, E. et al. (1994) Crop production and crop protection: estimated losses in major food and cash crops. Elsevier Science B. V., Amsterdam. 450-535.
Ohbayashi, K. et al. (2010) Development of a detection method of resistance to potato diseases and pests using DNA markers. 1. Detection methods of resistance to potato virus X, potato cyst nematodes, and late blight. Nagasakiken norin gijutsu kaihatsu senta kenkyu hokoku (Bull. Nagasaki Agri. Fore. Tech. Dev. Cen.) 1, 1-26 [In Japanese with English summary].

Phillips, M.S. et al. (1980) Screening for resistance to potato cyst nematode using closed containers. Ann. Appl. Biol. 96, 317-322.

Ritter, E. et al. (1991) RFLP mapping on potato chromosomes of 2 genes controlling extreme resistance to potato virus $\mathrm{X}$ (PVX). Mol. Gen. Genet. 227, 81-85.

Sakamoto, Y. et al. (2011) Resistance test method for potato common scab with non-bottom frame. Kyushu byougaichu kenkyukaiho (Kyushu Pl. Prot. Res.) 57, 14-18 [In Japanese].

Song, Y.S. \& Schwarzfischer, A. (2008) Development of STS markers for selection of extreme resistance (Rysto) to PVY and maternal pedigree analysis of extremely resistant cultivars. Am. J. Potato Res. 85, 159-170.

Stevenson, W.R. et al. (2001) Compendium of Potato Diseases. The American Phytopathological Society, St. Paul, MN.

Takeuchi, T. et al. (1996) Phylogenetic analysis of Streptomyces spp causing potato scab based on $16 \mathrm{~S}$ rRNA sequences. Int. J. Syst. Bacteriol. 46, 476-479.

Takeuchi, T. et al. (2008) High-resolution maps and DNA markers of the Potato virus $Y$ resistance gene Rychc and the potato cyst nematode resistance gene H1. Ikushugaku kenkyu (Breed. Res.) 10 (Suppl 1), 148 [In Japanese]. 